\begin{tabular}{|c|l|}
\hline Title & Highly luminescent tetranuclear Eu(III) complex with characteristic cavity space \\
\hline Author(s) & Koizuka, Toru; Kitagawa, Y uichi; Nakanishi, Takay uki; Fushimi, Koji; Hasegawa, Y asuchika \\
\hline Citation & $\begin{array}{l}\text { Inorganica chimica acta, 486, 240-244 } \\
\text { https://doi.org/40.1016/.ica.2018.10.063 }\end{array}$ \\
\hline Issue Date & 2019-02-24 \\
\hline Doc URL & http://hdl.handle.net/2115/80477 \\
\hline Rights & $\begin{array}{l}\text { ○ 2019. This manuscript version is made available under the CC-BY-NC-ND 4.0 license } \\
\text { http://creativecommons.org/icenses/by-nc-nd/4.0/ }\end{array}$ \\
\hline Rights(URL) & http://creativecommons.org/icenses/by-nc-nd/4.0/ \\
\hline Type & article (author version) \\
\hline hile Information & hase text(rev).pdf \\
\hline
\end{tabular}

Instructions for use 


\title{
Highly luminescent tetranuclear Eu(III) complex with characteristic cavity space
}

\author{
Toru Koizuka, ${ }^{1-2}$ Yuichi Kitagawa, ${ }^{3}$ Takayuki Nakanishi, ${ }^{4}$ Koji Fushimi, ${ }^{3}$ and Yasuchika Hasegawa ${ }^{3 *}$ \\ ${ }^{1}$ Semiconductor Development Division, Nichia Corporation, 1-1 Tatsumi, Anan, Tokushima 774-0001 \\ ${ }^{2}$ Graduate School of Chemical Sciences and Engineering, Hokkaido University, Kita 13, Nihi 8, Kita-ku, \\ Sapporo, Hokkaido 060-8628 \\ ${ }^{3}$ Faculty of Engineering, Hokkaido University, Kita 13, Nihi 8, Kita-ku, Sapporo, Hokkaido 060-8628 \\ ${ }^{4}$ Faculty of Industrial Science and Technology, Tokyo University of Science, 6-3-1, Niijuku, Katsushika-ku,
} Tokyo, $125-8585$

E-mail: hasegaway@eng.hokudai.ac.jp

\begin{abstract}
Novel luminescent tetranuclear Eu(III) complex $\left[\mathrm{Eu}(\mathrm{btfa})_{3}(\mathrm{salbn})\right]_{4}$ (btfa: benzoyltrifluoroacetonate, salbn: $N, N$-bis(salicylidene)-1,4-butanediamine) with characteristic cavity space is reported. The Eu(III) complex excited at $480 \mathrm{~nm}$ exhibits the highest photosensitized emission quantum yield (36\%) reported for similar previously reported tetranuclear Eu(III) complexes. The Eu(III) complex with salbn and btfa
\end{abstract}


also showed the spectral change under addition of $\mathrm{K}^{+}$and $\mathrm{Zn}^{2+}$ ions. In this study, we demonstrated metal ions sensor ability of a highly luminescent Eu(III) complex.

Keywords:

Tetranuclear; complex; Luminescence; Europium; Sensor

\section{Introduction.}

Metal-organic frameworks and porous coordination polymers (MOFs and PCPs) have been used in many applications including gas adsorption/storage, separation and catalysis based on their porous cavities. ${ }^{1-4}$ Developing effective detection methods for monitoring cavity are therefore highly necessary. ${ }^{5-7}$ The lanthanide metal-organic frameworks have been recognized as excellent materials for the effective detector because of their strong visible luminescence with narrow bandwidth. ${ }^{8-10}$ At the present stage, tetranuclear Eu(III) complexes as the basic models of PCPs have been attracted attention in soluble micro cavity. Hamacek and coworkers reported tetrahedral tetranuclear Eu(III) complex with tripodal ligands shows anion sensor in solution. ${ }^{11,12}$ Liu and coworkers achieved the highly selective probes for both anions and cations using tetranuclear Eu(III) complex with oxazoline-based ligands. ${ }^{13}$ Fan and Yang reported MOF type tetranuclear Eu(III) cluster showed the largest emission quantum yield (27.6\% ${ }^{14}$ in previously reported tetranuclear Eu(III) complexes. ${ }^{11-16}$ Their quantum yields are relatively low compared with the mononuclear $\mathrm{Eu}(\mathrm{III})$ complexes and coordination $\mathrm{Eu}(\mathrm{III})$ polymers. ${ }^{7}$ In particular, Eu(III) 
complexes with $\beta$-diketonate ligands show highly emission quantum yield (> 50\%). ${ }^{17-19}$ Recently, we found that $\mathrm{Eu}(\mathrm{III})$ complex composed of $\beta$-diketonate and Schiff base ligands exhibited strong red luminescence excited by visible light $(460 \mathrm{~nm}) \cdot{ }^{20}$ Visible-light sensitized Eu(III) complex is suitable for luminescent sensor because of the demand for less-harmful sensing reagents. Synthesis of tetranuclear $\mathrm{Eu}(\mathrm{III})$ complex composed of $\beta$-diketonate and Schiff base ligand leads to the development of highly luminescent $\mathrm{Eu}(\mathrm{III})$ complexes with sensing ability using visible light. In this study, we report that tetranuclear Eu(III) complex with characteristic porous structure exhibits highly photosensitized emission quantum yield owing to combination of Schiff base (salbn: $N, N^{\prime}$-bis(salicylidene)-1,4-butanediamine) and $\beta$-diketonate ligands (btfa: benzoyltrifluoroacetonate).

\section{Experimental}

General Methods. ${ }^{1} \mathrm{H}-\mathrm{NMR}$ spectra were recorded in $\mathrm{CD}_{2} \mathrm{Cl}_{2}$ on a JEOL ECS-400 (400 MHz) spectrometer; $\mathrm{CD}_{2} \mathrm{Cl}_{2}\left(\delta_{\mathrm{H}}=5.28 \mathrm{ppm}\right)$ was used as the internal reference. Elemental analyses were performed using MICRO CORDER JM10. Thermogravimetric analyses (TGA) were performed using an EXSTAR 6000 TG/DTA 6300 instrument (Seiko Instruments Inc.). Emission spectra were measured using a Horiba FluoroLog ${ }^{\circledR 3}$ spectrofluorometer. Photosensitized emission quantum yield was measured using a FP-6300 spectrofluorometer with an integration sphere (ILF-533). Infrared spectrum was recorded with a JASCO FTIR-4600 spectrometer. 
Single-Crystal X-ray crystallography. The orange crystal of the complex was mounted on a MiTeGen micromesh using paraffin oil. All measurements were made on a Rigaku RAXIS RAPID imaging plate area detector with graphite monochromated $\mathrm{MoK} \alpha$ radiation $(\lambda=0.71075 \AA)$ at $-150^{\circ} \mathrm{C}$. Corrections for decay and Lorentz polarization effects were made based on empirical absorption correction. The structure was solved by direct methods using SHELXS-97 ${ }^{21}$ and expanded using Fourier techniques. Structure refinements were performed by the full-matrix least-squares techniques in SHELXL-2014. ${ }^{21}$ All non-hydrogen atoms were refined anisotropically and hydrogen atoms were refined using riding model. The SQUEEZE program, ${ }^{22}$ which is a part of the PLATON package of crystallographic software, ${ }^{23}$ was used to calculate the solvent-disorder area and remove its contribution to the overall intensity data because solvent molecules in the unit cell were disordered and could not be modeled properly. All calculations were made using CrystalStructure (Rigaku Corporation, Tokyo, Japan, 2000-2014.), a crystallographic software package.

Materials. Europium chloride hexahydrate was purchased from Kanto Chemical Co., Inc. 4,4,4-trifluoro-1-phenyl-1,3-butanedione was obtained from Aldrich Chemical Company Inc. Salicylaldehyde, bis[2-(diphenylphosphino)phenyl]ether and 1,4-butanediamine were obtained from Tokyo Chemical Industry Co., Ltd. Potassium acetate and zinc acetate were purchased from Wako Pure Chemical Industries Ltd. All other solvents were reagent grade and used without further purification. 
Preparation of $N, N^{\prime}$-bis(salicylidene)-1,4-butanediamine (salbn). Salbn was prepared according to the literature. $^{20}$

Preparation of $\left[\mathrm{Eu}(\mathrm{btfa})_{3}\left(\mathrm{H}_{2} \mathrm{O}\right)_{2}\right]$ and $\quad\left[\mathrm{Eu}(\mathrm{btfa})_{3}(\mathrm{DPEPO})\right] \quad$ (DPEPO: bis[2-(diphenylphosphino)phenyl] ether oxide). [Eu(btfa $\left.)_{3}\left(\mathrm{H}_{2} \mathrm{O}\right)_{2}\right]$ and $\left[\mathrm{Eu}(\mathrm{btfa})_{3}(\mathrm{DPEPO})\right]$ were prepared according to the literature. ${ }^{24}$

Preparation of $\left[\mathbf{E u}(\mathbf{b t f a})_{3}(\text { salbn) }]_{4}\right.$. Prepared $\left[\mathrm{Eu}(\mathrm{btfa})_{3}\left(\mathrm{H}_{2} \mathrm{O}\right)_{2}\right](1.67 \mathrm{~g}, 2.0 \mathrm{mmol})$ was dissolved in of diethyl ether $(40 \mathrm{~mL})$. Salbn $(0.59 \mathrm{~g}, 2.0 \mathrm{mmol})$ was added to the solution. After stirring at room temperature for $24 \mathrm{~h}$, the precipitates were filtered and dried in vacuo. The yellow powder was obtained. Recrystallization from diethyl ether gave orange block crystals of the title lanthanide complex.

[Eu(btfa) $)_{3}(\text { salbn) }]_{4}$. Yield: $1.6 \mathrm{~g}(18 \%)$; Elemental analysis calcd (\%) for $\mathrm{C}_{192} \mathrm{H}_{152} \mathrm{Eu}_{4} \mathrm{~F}_{36} \mathrm{~N}_{8} \mathrm{O}_{32}$ : C, 52.71; H, 3.50; N, 2.56. Found: C, 52.49; H, 3.36; N, 2.50. IR (KBr): 2948-2863, 1647, 1626, 1616, 1536, 1489, 1319, 1287, 1242, $1133 \mathrm{~cm}^{-1}$.

\section{Results and discussion}

Single crystal of $\left[\mathrm{Eu}(\mathrm{btfa})_{3}(\mathrm{salbn})\right]_{4}$ was obtained by recrystallization from diethyl ether solution. The chemical and crystal structures of $\left[\mathrm{Eu}(\mathrm{btfa})_{3}(\mathrm{salbn})\right]_{4}$ are shown in Figure 1 . The crystallographic data is summarized in Table 1 . The coordination site of $\left[\mathrm{Eu}(\mathrm{btfa})_{3}(\mathrm{salbn})\right]_{4}$ comprises three btfa and two salbn 
ligands. Two hydroxy groups in one salbn ligand are bonded with two Eu(III) ions, which bear ring-typed tetranuclear $\mathrm{Eu}(\mathrm{III})$ complex. Intermolecular $\mathrm{CH} / \mathrm{F}, \mathrm{CH} / \pi$ and $\pi-\pi$ interactions were observed (Figure 2). We also found four trifluoromethyl groups in btfa ligands formed a small cavity in the center of ring-typed tetranuclear Eu(III) complex (Figure 1b). The cavity space (blue circle) is constructed along the c axis with a window size of $3.1 \AA$ (F-F distance), which is relatively small in comparison with previous tetranuclear complex. ${ }^{11-13,25}$. The space composed of fluorine atoms is expected to interact with metal ions.

Coordination geometry around $\mathrm{Eu}(\mathrm{III})$ ion is related to radiative rate constant and emission quantum efficiency. ${ }^{18}$ The continuous shape measure factor $S$ was calculated to estimate distortion degree of the coordination structure in the first coordination sphere based on the crystal structure data. The $S$ value is given by following equation.

$$
S=\min \frac{\sum_{k}^{N}\left|Q_{k}-P_{k}\right|^{2}}{\sum_{k}^{N}\left|Q_{k}-Q_{o}\right|^{2}} \times 100
$$

where $Q_{\mathrm{k}}$ is the vertices of an actual structure, $Q_{0}$ is the center of mass of an actual structure, $N$ is the number of vertices and $P_{\mathrm{k}}$ is the vertices of an ideal structure. ${ }^{26}$ The 8-coordinated lanthanide complexes exhibit square antiprism (SAP, point group: $\mathrm{D}_{4 \mathrm{~d}}$ ), trigonal dodecahedron (TDH, point group: $\mathrm{D}_{2 \mathrm{~d}}$ ) or biaugmented trigonal prism (BTP, point group: $\mathrm{C}_{2 \mathrm{v}}$ ) structures, according to evaluation of the $S$ values. From the calculation, $\left[\mathrm{Eu}(\mathrm{btfa})_{3}(\mathrm{salbn})\right]_{4}$ is categorized to be asymmetric coordination geometry of TDH $\left(\mathrm{D}_{2 \mathrm{~d}}\right)$ structure, which is expected to show highly efficient luminescence (Table 2). ${ }^{18}$ 
Emission spectrum of $\left[\mathrm{Eu}(\mathrm{btfa})_{3}(\mathrm{salbn})\right]_{4}$ in solid state is shown in Figure 3. The emission bands at 578,

$592,615,652$, and $698 \mathrm{~nm}$ were attributed to the $4 \mathrm{f}-4 \mathrm{f}$ transitions of $\mathrm{Eu}(\mathrm{III})\left({ }^{5} \mathrm{D}_{0^{-}}{ }^{7} \mathrm{~F}_{\mathrm{J}}: \mathrm{J}=0-4\right)$. The photosensitized emission quantum yields of tetranuclear Eu(III) complex excited at $480 \mathrm{~nm}$ was estimated to be $36 \%$, which is the highest photosensitized quantum yields in tetranuclear Eu(III) complexes. ${ }^{11-16}$

In order to evaluate a cation sensor ability of $\mathrm{Eu}(\mathrm{III})$ complex, potassium and zinc acetate $(10 \mathrm{mM})$ were added in ethanol solution with $\left[\mathrm{Eu}(\mathrm{btfa})_{3}(\mathrm{salbn})\right]_{4}(10 \mathrm{mM})$. The emission spectra of $\left[\mathrm{Eu}(\mathrm{btfa})_{3}(\mathrm{salbn})\right]_{4}$ with $\mathrm{K}^{+}$and $\mathrm{Zn}^{2+}$ ions in ethanol are shown in Figure 4. The spectra were normalized with respect to the magnetic dipole transition intensity at $592 \mathrm{~nm}$ (Eu: ${ }^{5} \mathrm{D}_{0}{ }^{7} \mathrm{~F}_{1}$ ), which is known to be insensitive to the environment surrounding Eu(III) ion. ${ }^{27,} 28$ The normalized emission intensity at $615 \mathrm{~nm}\left({ }^{5} \mathrm{D}_{0}-{ }^{7} \mathrm{~F}_{2}\right)$ of $\mathrm{Eu}$ (III) complex is decreased under addition of $\mathrm{K}^{+}$or $\mathrm{Zn}^{2+}$ ion. In general, the emission intensity at ${ }^{5} \mathrm{D}_{0}{ }^{7} \mathrm{~F}_{2}$ is depended on coordination geometry around $\mathrm{Eu}(\mathrm{III})$ ions. These results indicate that tetranuclear $\left[\mathrm{Eu}(\mathrm{btfa})_{3}(\mathrm{salbn})\right]_{4}$ is transformed from asymmetrical to symmetrical coordination structures around $\mathrm{Eu}(\mathrm{III})$ ions by addition of inorganic ions.

We also found broad emission band at around $450 \mathrm{~nm}$ of $\left[\mathrm{Eu}(\mathrm{btfa})_{3}(\mathrm{salbn})\right]_{4}$ with $\mathrm{Zn}^{2+}$ ion. Yuko Hasegawa has reported Schiff-based Eu complex with $\mathrm{Zn}^{2+}$ ion in $\mathrm{CHCl}_{3}$ shows blue emission. ${ }^{28}$ In our experiment, $\mathrm{Zn}^{2+}$ ion is captured by salbn parts. Mononuclear [Eu(btfa $\left.)_{3}(\mathrm{DPEPO})\right]$ (DPEPO: bis[2-(diphenylphosphino)phenyl] ether oxide) does not show the spectral change under addition of $\mathrm{K}^{+}$ ion (Figure 5). To clarify the sensing mechanism, we performed ${ }^{19}$ F-NMR measurements of $\left[\mathrm{Eu}(\mathrm{btfa})_{3}(\mathrm{salbn})\right]_{4}$ (ethanol-d6, $\left.10 \mathrm{mM}\right),\left[\mathrm{Eu}(\mathrm{btfa})_{3}(\mathrm{salbn})\right]_{4}$ (ethanol-d6, $\left.10 \mathrm{mM}\right)$ with $\mathrm{K}^{+}(0.2 \mathrm{eq})$, and 
$\left[\mathrm{Eu}(\mathrm{btfa})_{3}(\mathrm{salbn})\right]_{4}$ (ethanol-d6, $\left.10 \mathrm{mM}\right)$ with $\mathrm{Zn}^{2+}(0.2 \mathrm{eq})$ (Figure S1). The NMR signal of $\left[\mathrm{Eu}(\mathrm{btfa})_{3}(\mathrm{salbn})\right]_{4}$ with $\mathrm{Zn}^{2+}$ is similar with that of $\left[\mathrm{Eu}(\mathrm{btfa})_{3}(\mathrm{salbn})\right]_{4}(-80.1 \mathrm{ppm})$, indicating that $\mathrm{Zn}^{2+}$ ions is not fixed in cavity space of tetranuclear $\left[\mathrm{Eu}(\mathrm{btfa})_{3}(\mathrm{salbn})\right]_{4}$. On the other hand, the NMR signal of $\left[\mathrm{Eu}(\mathrm{btfa})_{3}(\mathrm{salbn})\right]_{4}$ with $\mathrm{K}^{+}$is slightly shifted to low magnetic field side $(-79.8 \mathrm{ppm})$ and significantly broadened, which originates from exchange interaction between fluorine atoms and $\mathrm{K}^{+}$. The characteristic cavity space in $\left[\mathrm{Eu}(\mathrm{btfa})_{3}(\text { salbn })\right]_{4}$ is considered to provide the sensing ability of $\mathrm{K}^{+}$ions.

\section{Conclusion}

In this study, we successfully synthesized tetranuclear Eu(III) complex with characteristic cavity space.

The characteristic cavity space provided the sensing ability of potassium ion based on visible light absorption. The tetranuclear $\mathrm{Eu}(\mathrm{III})$ complex is expected to be useful for novel luminescent metal ion sensor.

\section{Acknowledgements}

We are particularly grateful for experimental assistance by Professor H. Ito and Assistant Professor T.

Seki in Hokkaido Univ. We appreciate the support of Professor M. Kato and Assistant Professor M.

Yoshida in Hokkaido University for the single crystal X ray structure analysis. 


\section{Notes}

The Cambridge Crystallographic Data Centre provides the supplementary crystallographic data for

$\left[\mathrm{Eu}(\mathrm{btfa})_{3}(\mathrm{salbn})\right]_{4}\left(\mathrm{CCDC}-\mathrm{No}_{1}\right.$ 1836246). This research did not receive any specific grant from funding

agencies in the public, commercial, or not-for-profit sectors.

\section{References}

[1] S. Kitagawa, R. Kitaura, S. Noro, Angew. Chem. Int. Ed. 2004, 43, 2334-2375.

[2] A. Kobayashi, A. Sugiyama, T. Ohba, Y. Suzuki, H.-C. Chang, M. Kato, Chem. Lett. 2014, 43, 1070-1072.

[3] S. Noro, J. Mizutani, Y. Hijikata, R. Matsuda, H. Sato, S. Kitagawa, K. Sugimoto, Y. Inubushi, K. Kubo, T. Nakamura, Nat. Commun. 2015, 6, 1-9.

[4] H. Furukawa, N. Ko, Y. B. Go, N. Aratani, S. B. Choi, E. Choi, A. Ö. Yazaydin, R. Q. Snurr, M. O’Keeffe, J. Kim, O. M. Yaghi, Science 2010, 329, 424-428.

[5] S. Furukawa, Y. Sakata, S. Kitagawa, Chem. Lett. 2013, 42, 570-576.

[6] N. Yanai, K. Kitayama, Y. Hijikata, H. Sato, R. Matsuda, Y. Kubota, M. Takata, M. Mizuno, T. Uemura, S. Kitagawa, Nat. Mater. 2011, 10, 787-793.

[7] J. C. G. Bünzli, Chem. Rev. 2010, 110, 2729-2755.

[8] Z.-H. Zhou, W.-W. Dong, Y.-P. Wu, J. Zhao, D.-S. Li, T. Wu, X. Bu, Inorg. Chem. 2018, 57, 3833-3839.

[9] R.-Z. Wu, X. Yang, L.-W. Zhang, P.-P. Zhou, Dalt. Trans. 2017, 46, 9859-9867.

[10]B. Yan, Acc. Chem. Res. 2017, 50, 2789-2798.

[11]B. El Aroussi, L. Guénée, P. Pal, J. Hamacek, Inorg. Chem. 2011, 50, 8588-8597.

[12] J. Hamacek, D. Poggiali, S. Zebret, E. Aroussi, Chem. Commun. 2012, 1281-1283.

[13] C. Liu, R. Zhang, C. Lin, L. Zhou, L. Cai, J. Kong, S. Yang, K. Han, Q. Sun, J. Am. Chem. Soc. 2017, 139, 12474-12479.

[14]H. Zhang, R. Fan, W. Chen, J. Fan, Y. Dong, Y. Song, X. Du, P. Wang, Y. Yang, Cryst. Growth Des. 2016, 16, 5429-5440.

[15] X. L. Li, L. X. Shi, L. Y. Zhang, H. M. Wen, Z. N. Chen, Inorg. Chem. 2007, 46, 10892-10900.

[16] O. A. Gerasko, E. A. Mainicheva, M. I. Naumova, M. Neumaier, M. M. Kappes, S. Lebedkin, D. Fenske, V. P. Fedin, Inorg. Chem. 2008, 47, 8869-8880. 
[17] Y. Hirai, T. Nakanishi, Y. Kitagawa, K. Fushimi, T. Seki, H. Ito, H. Fueno, K. Tanaka, T. Satoh, Y. Hasegawa, Inorg. Chem. 2015, 54, 4364-4370.

[18]K. Miyata, T. Nakagawa, R. Kawakami, Y. Kita, K. Sugimoto, T. Nakashima, T. Harada, T. Kawai and Y. Hasegawa, Chem. - Eur. J. 2011, 17, 521-528.

[19] S. V. Eliseeva, D. N. Pleshkov, K. A. Lyssenko, L. S. Lepnev, J.-C. G. Bünzli and N. P. Kuzmina, Inorg. Chem. 2010, 49, 9300-9311.

[20] T. Koizuka, K. Yanagisawa, Y. Hirai, Y. Kitagawa, T. Nakanishi, K. Fushimi, Y. Hasegawa, Inorg. Chem. 2018, 57, 7097-7103.

[21]G. M. Sheldrick, Acta Crystallogr. Sect. A 2008, 64, 112-122.

[22] P. van der Sluis, A. L. Spek, Acta Crystallogr. Sect. A 1990, 46, 194-201.

[23] A. L. Spek, Acta Crystallogr. Sect. A 1990, 46, C34.

[24] T. Koizuka, M. Yamamoto, Y. Kitagawa, T. Nakanishi, K. Fushimi, Y. Hasegawa, Bull. Chem. Soc. Jpn. 2017, 90, 1287-1292.

[25] T. Y. Bing, T. Kawai and J. Yuasa, J. Am. Chem. Soc. 2018, 140, 3683-3689

[26]D. Casanova, M. Llunell, P. Alemany, S. Alvarez, Chem. - Eur. J. 2005, 11, 1479-1494.

[27] C.Görller-Walrand, L. Fluyt, A. Ceulemans, W. T. Carnall, J. Chem. Phys. 1991, 95, 3099-3106.

[28] M. H. V. Werts, R. T. F. Jukes, J. W. Verhoeven, Phys. Chem. Chem. Phys. 2002, 4, 1542-1548.

[29] Y. Hasegawa, S. Saitou, S. Tamaki, H. Yajima, M. Tadokoro, Helv. Chim. Acta, 2009, 92, 2565-2575.

Figure caption

Figure 1. (a) Chemical structure of tetranuclear $\left[\mathrm{Eu}(\mathrm{btfa})_{3}(\mathrm{salbn})\right]_{4}$, (b) ORTEP view of $\left[\mathrm{Eu}(\mathrm{btfa})_{3}(\mathrm{salbn})\right]_{4}$ (blue circle is small cavity) and (c) packing structure of $\left[\mathrm{Eu}(\mathrm{btfa})_{3}(\mathrm{salbn})\right]_{4}$.

Figure 2. Intermolecular (a) $\mathrm{CH} / \mathrm{F}$ interactions (red line), (b) $\mathrm{CH} / \pi$ interactions (blue line) and (c) $\pi-\pi$ interactions (green line) of the tetranuclear Eu(III) complex. 
Figure 3. Emission (right) and excitation (left) spectra of Eu(III) complex excited at $480 \mathrm{~nm}$ in solid state at room temperature.

Figure 4. Emission spectra of a) Eu(III) complex in ethanol (10 mM), b) Eu(III) complex in ethanol (10 $\mathrm{mM}$ ) with potassium acetate $(0.2 \mathrm{eq})$, and c) Eu(III) complex in ethanol $(10 \mathrm{mM})$ with zinc acetate $(0.2$ eq) excited at $380 \mathrm{~nm}$ at room temperature.

Figure 5. Emission spectra of a) $\left[\mathrm{Eu}(\mathrm{btfa})_{3}(\mathrm{DPEPO})\right]$ in ethanol $(0.2 \mathrm{mM}$, black line) and b) $\left[\mathrm{Eu}(\mathrm{btfa})_{3}(\mathrm{DPEPO})\right]$ in ethanol $(0.2 \mathrm{mM}$ with potassium acetate, $0.2 \mathrm{eq}$, red broken line) excited at 380 $\mathrm{nm}$ at room temperature.

Table 1. X-ray crystal data of the Eu(III) complex

\begin{tabular}{|c|c|}
\hline & {$\left[\mathrm{Eu}(\mathrm{btfa})_{3}(\mathrm{salbn})\right]_{4}$} \\
\hline chemical formula & $\mathrm{C}_{192} \mathrm{H}_{152} \mathrm{Eu}_{4} \mathrm{~F}_{36} \mathrm{~N}_{8} \mathrm{O}_{32}$ \\
\hline fw & 4375.13 \\
\hline crystal system & tetragonal \\
\hline space group & $P \overline{4} \quad($ no. 81$)$ \\
\hline$a(\AA)$ & $28.5364(6)$ \\
\hline$c(\AA)$ & $11.7218(3)$ \\
\hline vol. $\left(\AA^{3}\right)$ & $9545.4(4)$ \\
\hline
\end{tabular}


$d_{\text {calcd }}\left(\mathrm{g} \mathrm{cm}^{-3}\right)$

1.522

temp $\left({ }^{\circ} \mathrm{C}\right)$

$\mu_{\mathrm{MoK \alpha}}\left(\mathrm{cm}^{-1}\right)$

13.998

$\max 2 \theta(\operatorname{deg})$

55.0

no. of reflns collected

84669

no. of independent reflns

21790

$\boldsymbol{R}_{\text {int }}$

0.0764

$R_{1}$

0.0495

$\mathbf{w} \boldsymbol{R}_{2}$

0.1063

Goodness of Fit

1.020 
Table 2. S-factors of the tetranuclear Eu(III) complex

\begin{tabular}{cccc}
\hline Eu & SAP( $\left(D_{4 \mathrm{~d}}\right)$ & TDH $\left(\mathrm{D}_{2 \mathrm{~d}}\right)$ & $\mathrm{BTP}\left(\mathrm{C}_{2 \mathrm{v}}\right)$ \\
\hline 1 & 1.872 & 1.209 & 1.249 \\
2 & 1.872 & 1.209 & 1.249 \\
3 & 1.872 & 1.209 & 1.249 \\
4 & 1.872 & 1.209 & 1.249 \\
\hline
\end{tabular}




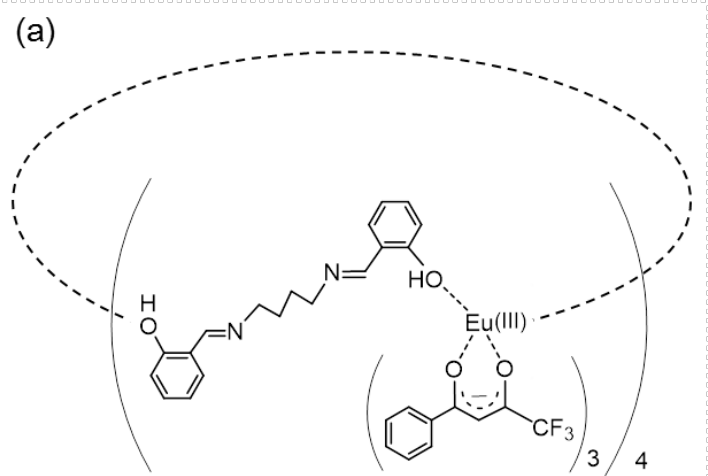

(b)
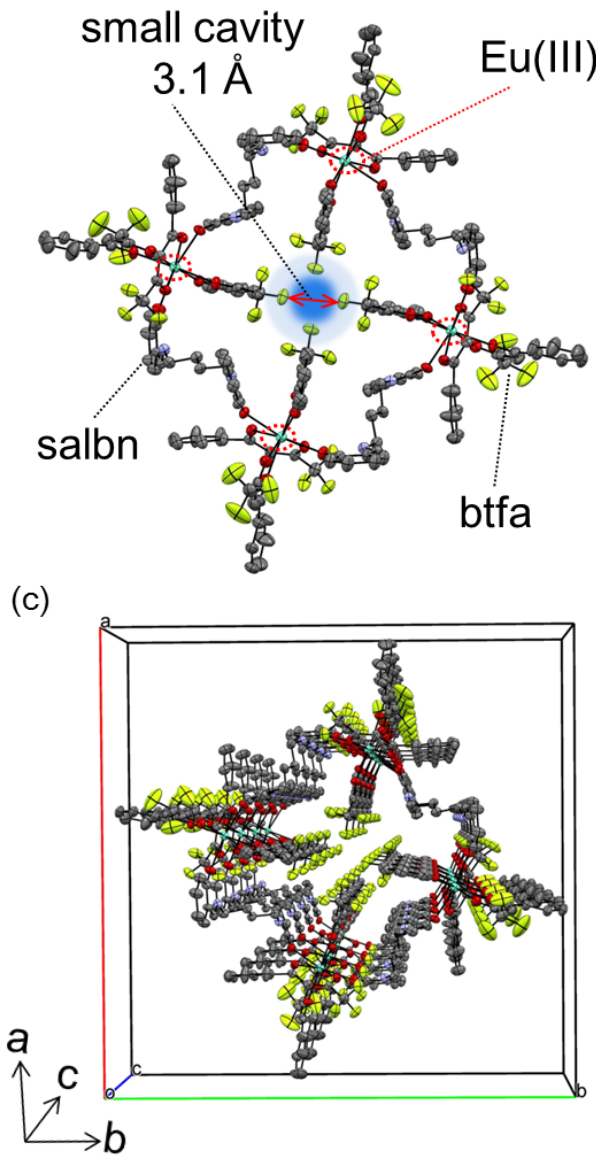
Figure 2.

(a)

(b)
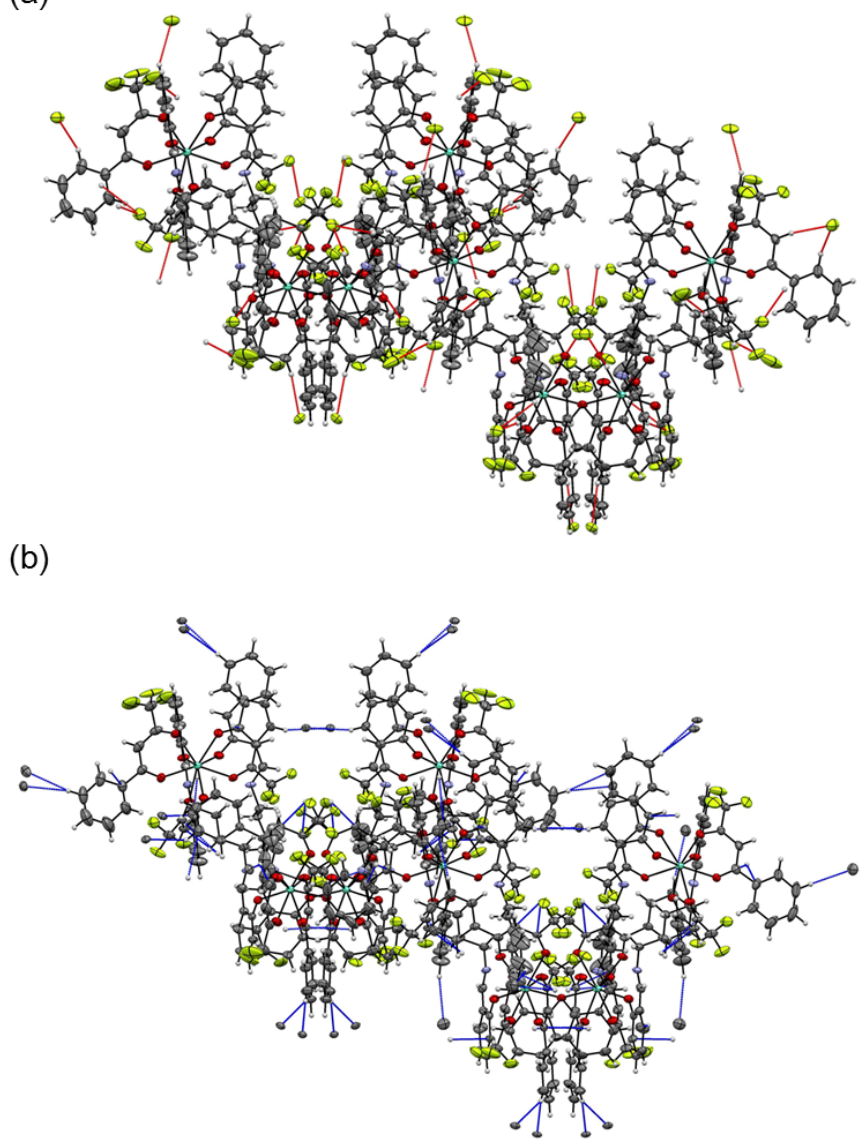

(c)

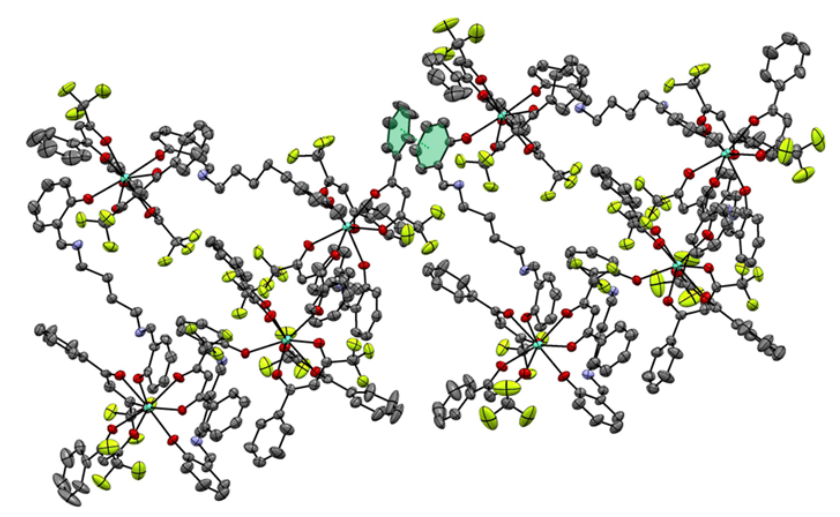


Figure 3.

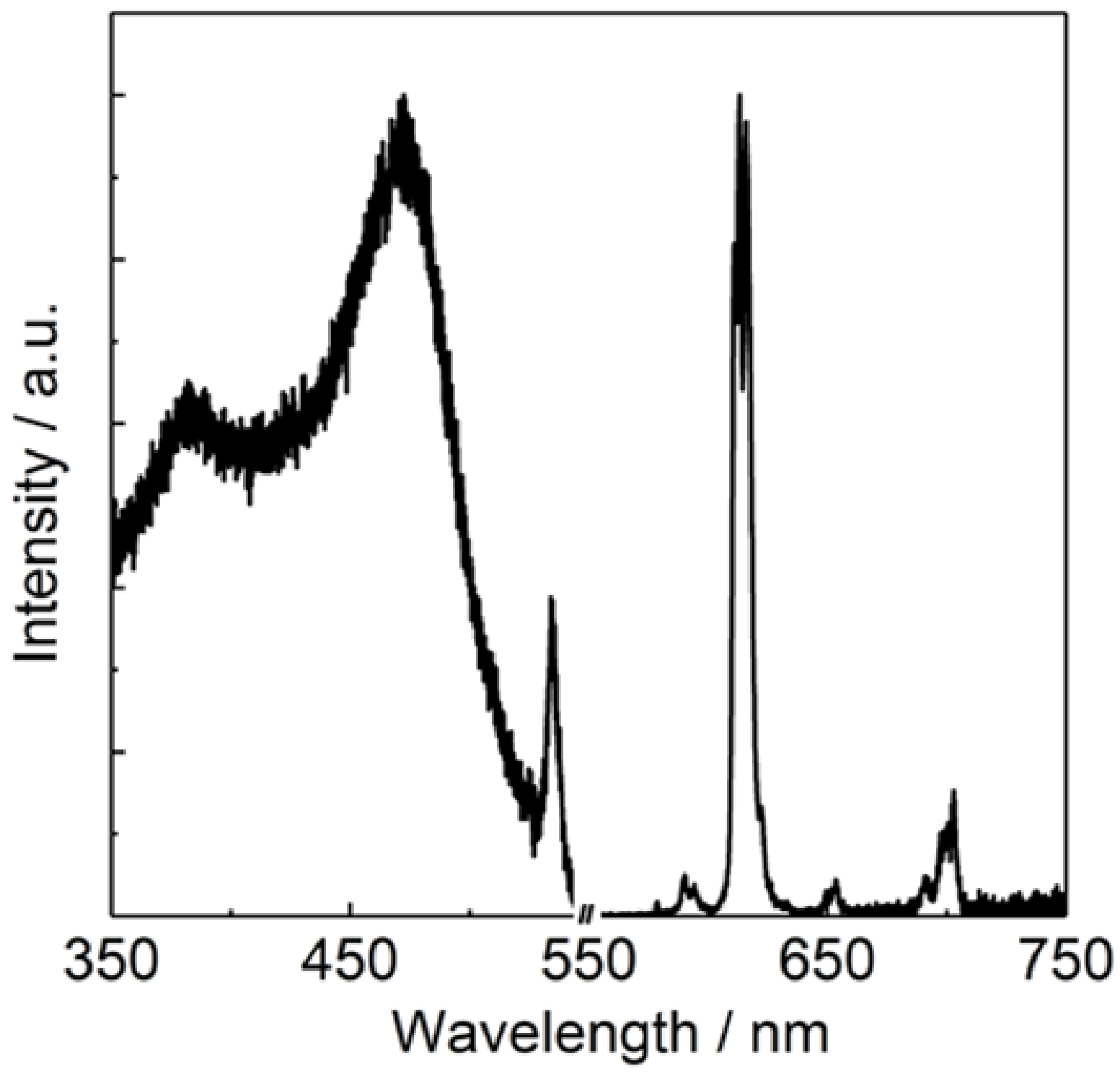


Figure 4.

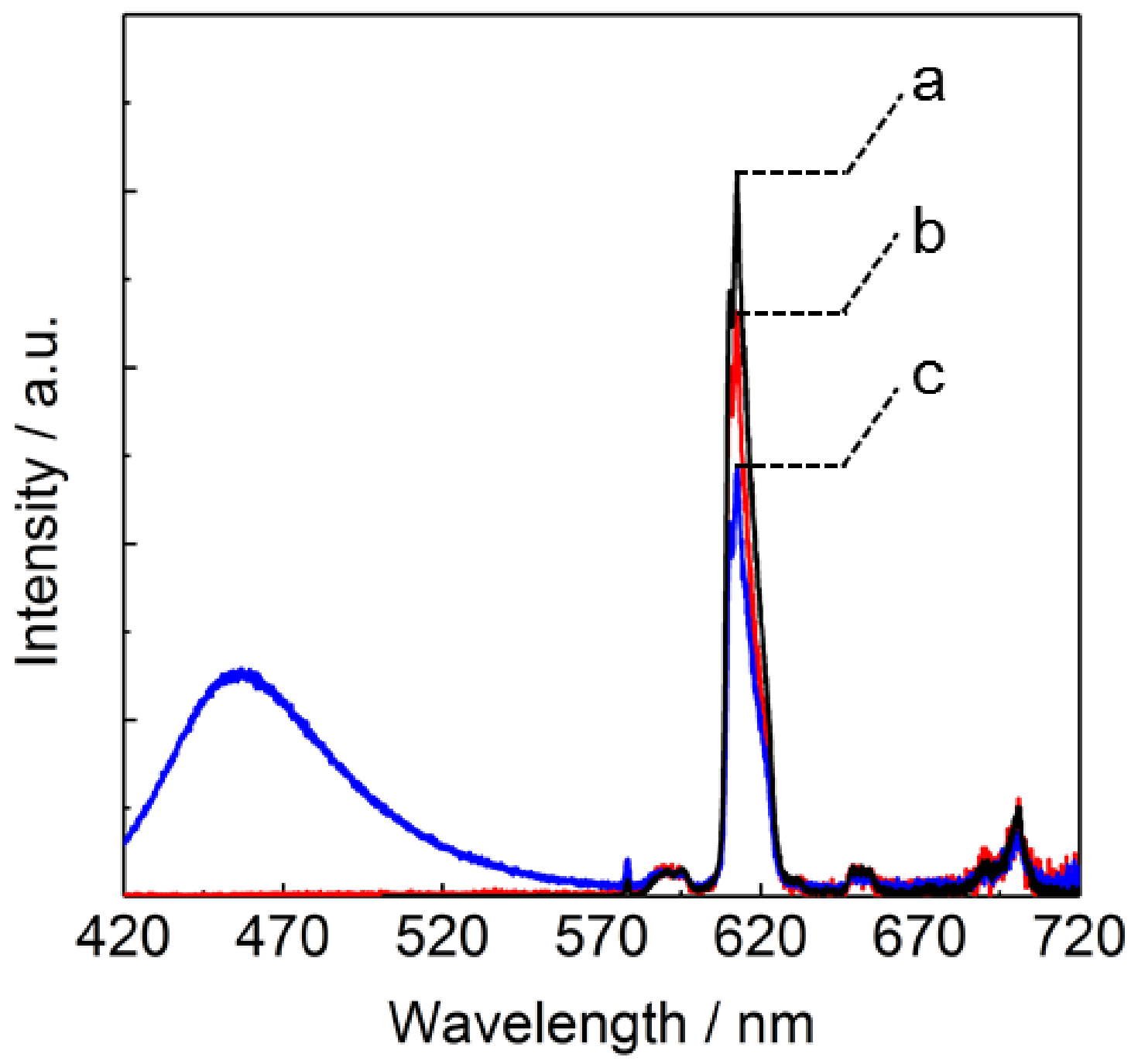


Figure 5.

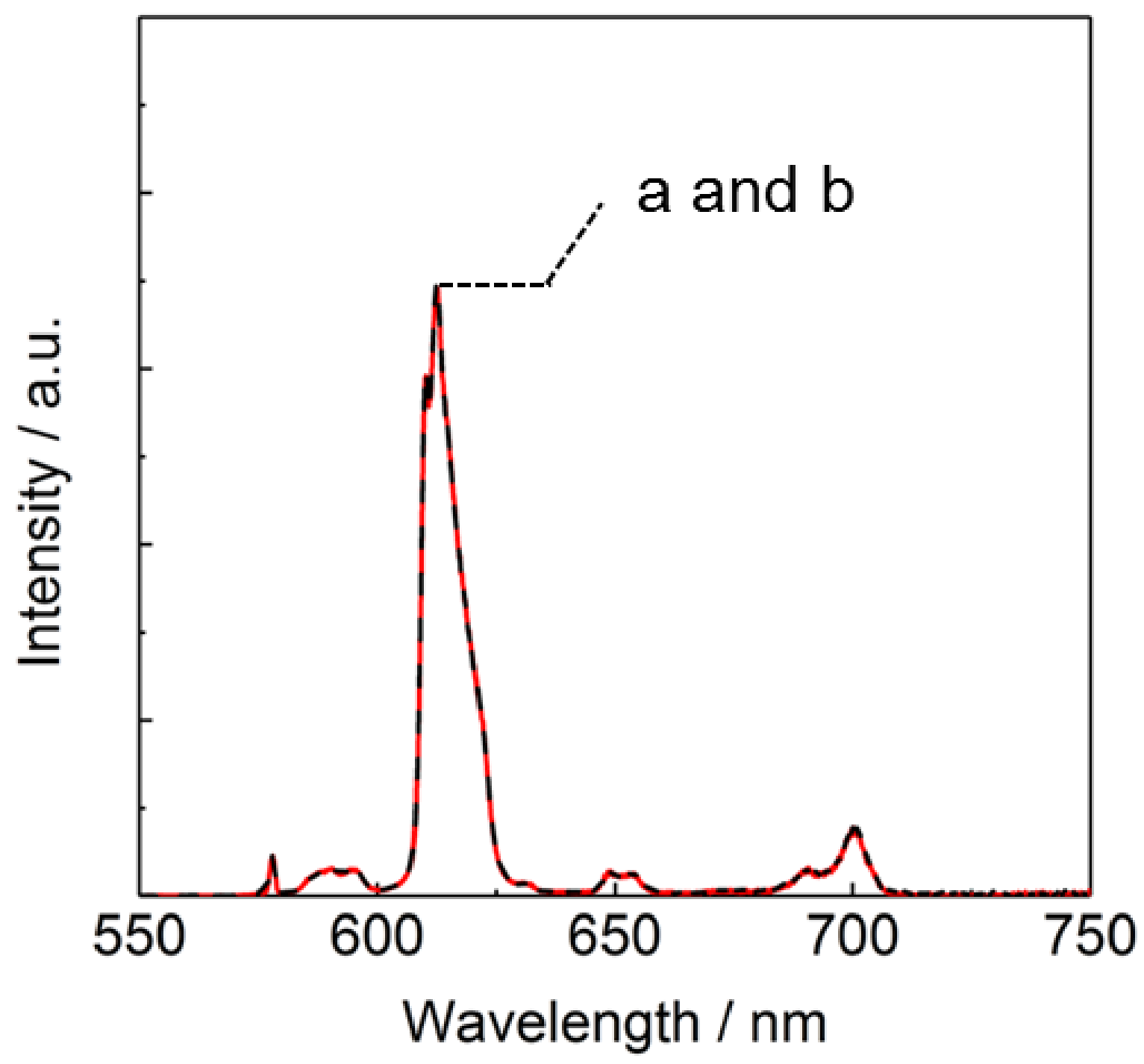

